\title{
Insights into the evolution of the snail superfamily from metazoan wide molecular phylogenies and expression data in annelids Pierre Kerner ${ }^{1,2,3}$, Johanne Hung2 ${ }^{2}$ Julien Béhague ${ }^{1,2}$, Martine Le Gouar², Guillaume Balavoine ${ }^{1,2}$ and Michel Vervoort*1,2,3
}

\author{
Address: ${ }^{1}$ Programme Development and Neurobiology, Institut Jacques Monod, UMR 7592 CNRS/Université Paris Diderot - Paris 7, 15 rue \\ Hélène Brion, 75205 Paris Cedex 13, France, ²Evolution et Développement des Métazoaires, Centre de Génétique Moléculaire- FRE 3144 CNRS, \\ 1, av. de la terrasse, 91198 Gif-sur-Yvette, France and ${ }^{3}$ UFR des Sciences du Vivant, Université Paris Diderot - Paris 7, 5, rue Marie-Andrée Lagroua \\ Weill-Hallé, 75205 Paris Cedex 13, France \\ Email: Pierre Kerner - kerner@cgm.cnrs-gif.fr; Johanne Hung - sadako_jh@hotmail.com; Julien Béhague - behague@cgm.cnrs-gif.fr; Martine Le \\ Gouar - legouar@cgm.cnrs-gif.fr; Guillaume Balavoine - balavoine@cgm.cnrs-gif.fr; Michel Vervoort* - vervoort@cgm.cnrs-gif.fr \\ * Corresponding author
}

Published: 9 May 2009

BMC Evolutionary Biology 2009, 9:94 doi:10.1|86/147|-2|48-9-94

This article is available from: http://www.biomedcentral.com/|47|-2/48/9/94

(C) 2009 Kerner et al; licensee BioMed Central Ltd.

This is an Open Access article distributed under the terms of the Creative Commons Attribution License (http://creativecommons.org/licenses/by/2.0), which permits unrestricted use, distribution, and reproduction in any medium, provided the original work is properly cited.
Received: 5 December 2008

Accepted: 9 May 2009

\begin{abstract}
Background: An important issue concerning the evolution of duplicated genes is to understand why paralogous genes are retained in a genome even though the most likely fate for a redundant duplicated gene is nonfunctionalization and thereby its elimination. Here we study a complex superfamily generated by gene duplications, the snail related genes that play key roles during animal development. We investigate the evolutionary history of these genes by genomic, phylogenetic, and expression data studies.
\end{abstract}

Results: We systematically retrieved the full complement of snail related genes in several sequenced genomes. Through phylogenetic analysis, we found that the snail superfamily is composed of three ancestral families, snail, scratchA and scratchB. Analyses of the organization of the encoded proteins point out specific molecular signatures, indicative of functional specificities for Snail, ScratchA and ScratchB proteins. We also report the presence of two snail genes in the annelid Platynereis dumerilii, which have distinct expression patterns in the developing mesoderm, nervous system, and foregut. The combined expression of these two genes is identical to that of two independently duplicated snail genes in another annelid, Capitella spl, but different aspects of the expression patterns are differentially shared among paralogs of Platynereis and Capitella.

Conclusion: Our study indicates that the snail and scratchB families have expanded through multiple independent gene duplications in the different bilaterian lineages, and highlights potential functional diversifications of Snail and ScratchB proteins following duplications, as, in several instances, paralogous proteins in a given species show different domain organizations. Comparisons of the expression pattern domains of the two Platynereis and Capitella snail paralogs provide evidence for independent subfunctionalization events which have occurred in these two species. We propose that the snail related genes may be especially prone to subfunctionalization, and this would explain why the snail superfamily underwent so many independent duplications leading to maintenance of functional paralogs. 


\section{Background}

When dealing with the evolution of large gene families, an ideal framework is to use resolved and comprehensive phylogenies both of the species concerned and of the different genes involved. This is even more necessary when one wants to assess the ancestral function of the first representatives of a gene family. Indeed, involvement of some gene families in conserved developmental processes can highlight the evolutionary history of particular structures, but incautious established phylogenies can lead to dubious conclusions especially when paralogous relationships between gene representatives in one species are overlooked. Besides, careful phylogenies of gene families with multiple representatives in many species can yield interesting results concerning the molecular evolution of genes, in particular with regard to gene duplication events.

An interesting example of a large and complex gene family is represented by the snail genes encoding $\mathrm{C} 2 \mathrm{H} 2$ zinc fingers transcription factors $[1,2]$. Since the cloning in Drosophila melanogaster of the snail gene [3] - the founding member of the family - numerous snail related genes were isolated in many metazoan species belonging to Arthropods (e.g. [4-7]), Nematodes [4], Vertebrates (e.g. [1,815]), non-vertebrate Deuterostomes (e.g. [16-19]), Cnidarians (e.g. [20-22]), and Lophotrochozoans [23-25]. In many species, more than one snail related gene was found, indicating the occurrence of gene duplication events. In Drosophila for example, in addition to snail, five paralogs were found, two with important sequence similarity to snail, escargot and worniu $[26,27]$, and three more, scratch [28], scratch-like 1 and scratch-like 2 [1] that are more distantly related to snail paralogs than to each other. Similarly, in vertebrate species, multiple snail-like and scratchlike genes were identified, e.g. the three mouse snail-like and two scratch-like genes (reviewed in $[1,2]$ ). Based on molecular phylogenetic analyses as well as careful examination of the exon/intron organization of the genes and domain organization of the proteins, it has been suggested that snail related genes form a superfamily consisting of two independent families, snail (stricto sensu) and scratch, established early during bilaterian evolution and accompanied by increased complexity through duplication events in several bilaterian lineages $[1,2]$.

The complexity of the snail superfamily is exemplified when assessing the different functions of these genes. snail genes seem to play numerous and seemingly unrelated roles during development. In Drosophila, for example, snail is expressed from the early syncitial blastoderm to late stages of development, and is involved in the formation of numerous structures and tissues, such as the invaginating mesoderm $[3,29]$, the anterior and posterior midgut $[29,30]$, the wing, haltere and genital imaginal discs [31], as well as the Central and Peripheral Nervous
System (CNS and PNS) in which snail acts in both neural precursors, such as Neuroblasts (NBs) and Ganglion Mother Cells (GMCs), and postmitotic neurons $[26,32,33]$. In several of these tissues, snail has redundant roles with its paralogs, for example with escargot in the wing and haltere discs [31] and with both escargot and worniu in the CNS and PNS [26,32,33]. In agreement with their involvement in the formation of very diverse structures, Drosophila snail/escargot/worniu genes function in several cellular processes, such as the control of cell shape changes, cell movements, asymmetric cell divisions, cell fate specification and cell differentiation (e.g. $[29,31,32,34-36])$. scratch is mainly expressed in the developing nervous system formation and has been shown to promote neuronal development in the CNS [28].

snail genes (but not scratch genes) have been studied in a few other protostome species and their expression patterns, while showing some similarities, are not easily comparable with those of Drosophila snail genes. In the short germ-band insect Tribolium castaneum, a snail ortholog expression has been shown in the early invaginating mesoderm, like in Drosophila, but no other expression sites have been reported [5]. In the spiders Cupiennius salei and Achaearanea tepidariorum, a single snail gene has been isolated and its expression and function seem to be restricted to the formation of the nervous system [6,7]. In the mollusk Patella vulgata, the two isolated snail genes seem to be only expressed in unknown ectodermal derivatives [25], while in the annelids Helobdella robusta and Capitella sp.I, snail genes are expressed in the developing nervous system, parts of the gut, and the differentiating mesoderm $[23,24]$. Much more is known about vertebrate snail genes that have been shown to have multiple roles during development $[1,2,37]$. This includes control of neural crest specification and delamination, mesoderm specification, left-right asymmetry, the triggering of Epithelial to Mesenchymal Transition (EMT), and the development of limbs, lens and some mesodermal derivatives (e.g. $[1,2,9,11,37,38])$. In most of these processes, snail genes are involved in the control of cell movements and behaviors which has been proposed as the unifying theme of snail genes functions, not only in vertebrates, but also more generally in all bilaterians, as in many instances snail genes are expressed in migrating, invaginating or delaminating cells and are responsible for these specific cell behaviors (reviewed in $[2,37]$ ). Strikingly, expressions consistent with this type of functions have been described in cnidarians where snail genes are expressed in the invaginating endoderm of a sea anemone $[20,21]$ and in internalized mesenchymal-like cells of a jellyfish [22], suggesting a possible ancestral role of snail genes in the regulation of cell motility among metazoans. 
Several previously published studies addressed the evolution of the snail superfamily in metazoans $[1,2,12,19,37]$. In this article, we significantly extend these analyses by systematically retrieving the full complement of snail related genes in several newly-sequenced genomes as well as many previously cloned genes from this superfamily. We also cloned two snail related genes from the polychaete annelid Platynereis dumerilii (Pdu-snail1 and Pdusnail2). We conducted multiple phylogenetic analyses on this large dataset and thoroughly analyzed the protein domain organization of the Snail related proteins. Our study allowed us to conclude that (i) the snail superfamily can be subdivided into three distinct families, snail, scratch $A$ and scratch $B$, the latter two forming the larger scratch family; (ii) many independent duplications occurred throughout the evolutionary history of the snail superfamily and changes in the domain organization of the proteins are associated with some duplications. We also studied the expression patterns of Pdu-snail1 and Pdusnail2 and found that these genes are expressed in distinct patterns in the developing mesoderm and nervous system, suggesting bilaterian-wide conservation of snail functions in these tissues. In addition, the comparison of Platynereis snail genes expression patterns with those of their orthologs in another annelid,Capitella sp.I, highlights a striking example of expression patterns swapping among paralogs, suggestive of the occurrence of subfunctionalization events.

\section{Results and discussion}

\section{The snail superfamily in metazoans}

As the starting point of this study, we cloned two putative snail genes in the annelid Platynereis dumerilii by PCR using degenerated primers and RACE protocols (see Methods). We then used these sequences, as well as known snail and scratch genes from arthropods and vertebrates, as seeds in systematic BLAST searches to retrieve snail superfamily representatives in several metazoan species, in particular species for which fully-sequenced genomes are available. This led to the identification of 89 snail related sequences (snail and scratch families altogether) from various species covering the main animal lineages, 10 ecdysozoan species ( 1 nematode and 9 arthropods -7 insects, 1 crustacean and 1 chelicerate); 11 deuterostomes ( 5 vertebrates, 2 urochordates, 2 echinoderms, 1 cephalochordate and 1 hemichordate); 4 lophotrochozoans (2 mollusks and 2 annelids); 2 cnidarians; and 1 placozoan. A summary of the studied species with the number of identified snail related genes is shown in Table 1. A list of all the identified sequences can be found in Additional file 1.

Strikingly, in every animal species (except one - Ciona intestinalis) whose genome is completely sequenced, we found at least one snail-like and one scratch-like gene, con-
Table I: Number of snail, scratchA, and scratchB genes found in the different studied species

\begin{tabular}{|c|c|c|c|c|}
\hline Species & Snail & ScratchA & ScratchB & Total \\
\hline Acropora millepora & 1 & - & - & 1 \\
\hline Aedes aegypti & 1 & - & - & 1 \\
\hline Anolis carolinensis & 2 & - & - & 2 \\
\hline Anopheles gambiae & $\mathbf{I}$ & I & 2 & 4 \\
\hline Apis mellifera & $\mathbf{I}$ & $\mathbf{I}$ & 2 & 4 \\
\hline Branchiostoma floridae & $\mathbf{I}$ & $\mathbf{I}$ & $\mathbf{I}$ & 3 \\
\hline Caenorhabditis elegans & $\mathbf{I}$ & - & I & 2 \\
\hline Capitella spl & 2 & I & 3 & 6 \\
\hline Ciona intestinalis & $\mathbf{I}$ & - & - & I \\
\hline Cupiennius salei & 1 & - & - & 1 \\
\hline Danio rerio & 4 & - & 3 & 7 \\
\hline Daphnia pulex & $\mathbf{I}$ & $\mathbf{I}$ & 2 & 4 \\
\hline Drosophila melanogaster & 3 & I & 2 & 6 \\
\hline Drosophila pseudoobscura & 3 & $\mathbf{I}$ & 2 & 6 \\
\hline Halocynthia roretzi & 1 & - & - & 1 \\
\hline Homo sapiens & 4 & - & 2 & 6 \\
\hline Lottia gigantea & 2 & $\mathbf{I}$ & $\mathbf{I}$ & 4 \\
\hline Lytechinus variegatus & 1 & - & - & 1 \\
\hline Mus musculus & 3 & - & 2 & 5 \\
\hline Nasonia vitripennis & I & $\mathbf{I}$ & I & 3 \\
\hline Nematostella vectensis & 2 & - & I & 3 \\
\hline Patella vulgata & 2 & - & - & 2 \\
\hline Platynereis dumerilii & 2 & - & - & 2 \\
\hline Saccoglossus kowalevskii & 1 & - & 1 & 2 \\
\hline Strongylocentrotus purpuratus & I & $\mathbf{I}$ & I & 3 \\
\hline Tribolium castaneum & I & I & 2 & 4 \\
\hline Trichoplax adhaerens & I & - & I & 2 \\
\hline
\end{tabular}


firming the ancestry of these two gene families and their strong conservation during animal evolution. An interesting exception is the sponge Amphimedon queenslandica in whose genome we were unable to find any gene with significant sequence similarity to snail and/or scratch genes. Extensive blast searches against several other publicly available databases (such as EST databases) also failed to identify snail related genes from sponges (not shown). Sponges are widely considered as the sister group of all other animals (which constitute the so-called eumetazoans) [39] and therefore the absence of snail related genes in Amphimedon may suggest that the snail superfamily evolved after the divergence between sponges and eumetazoans and may therefore constitute a molecular synapomorphy of the latter. Alternatively, snail related genes may have been secondarily lost in the Amphimedon lineage. This second alternative should be considered as the most plausible if we take in consideration some recently obtained metazoan phylogenies that suggest that sponges may not be the most basal animals $[40,41]$. We also failed to detect any snail related gene in the fully sequenced genome of species outside metazoans, including the choanoflagellate Monosiga brevicollis, a close relative of animals (not shown).

Therefore, we conclude that the snail superfamily originated early in the metazoan lineage and has been strongly conserved during metazoan evolution. The presence of several snail related genes in most species prompted us to further study the evolution of the family by phylogenetic and protein domain organization analyses.

\section{The snail superfamily consists of 3 evolutionary conserved families (snail, scratchA and scratchB) and its evolution has been shaped by numerous gene duplication events}

We constructed a multiple alignment of conserved domains from 89 identified Snail related proteins (Additional file 2) and used this alignment to construct phylogenetic trees using different phylogenetic methods (see Methods). The trees obtained with the different methods were broadly congruent and a representative tree is shown in Figure 1. A similar tree topology was obtained using an alignment including whole sequences (not shown). In order to test the monophyly of the snail superfamily and to root our phylogenetic trees, we used as outgroup a family of uncharacterized Zinc finger proteins which are only present in the genomes of insects (known as CG15269 in Drosophila) and which show sequence similarity to the Snail related proteins. As expected, we found that all the Snail related proteins form a strongly supported monophyletic group which is separated into two well supported families, snail and scratch (Figure 1). Interestingly, the scratch family is separated further into two subgroups that we named scratchA and scratchB. Both subfamilies regroup scratch representatives belonging to the three main bilate-
Table I: Number of snail, scratchA, and scratchB genes found in the different studied species (Continued)

\begin{tabular}{lllll}
\hline Xenopus laevis & 3 & - & - & 3 \\
\hline
\end{tabular}

In bold are indicated species for which whole genome sequences have been used.

rian lineages (deuterostomes, lophotrochozoans and ecdysozoans), suggesting an early duplication of a single scratch gene before the divergence of these three lineages. The presence of a single scratch gene in the non bilaterian species Nematostella vectensis and Trichoplax adhaerens (Table 1) suggests that this duplication event occurred during early bilaterian evolution, after the divergence with cnidarians and placozoans. However, as the single Nematostella and Trichoplax Scratch sequences have a weak tendency to group with the bilaterian ScratchB proteins (Figure 1), we cannot rule out the possibility that the Nematostella and Trichoplax genes are bona fide scratchB genes and therefore that the scratch $A$ representatives were lost in these two species.

We also defined the genomic position of the snail and scratch genes of every species whose genome is completely sequenced (Additional file 3). While in most species snail and scratch genes are dispersed to different chromosomes, genomic scaffolds, or contigs, we found a few cases of genomic linkages (colored gene names in Additional file 3 ). Most of these associations concern either two or more snail genes (in Capitella, Drosophila, and Lottia), or two or more scratchB genes (in Anopheles, Apis, Daphnia, Drosophila, and Tribolium), and likely correspond to relatively recent tandem duplications that occurred in some ancestors of these species (see the phylogenetic analysis reported in the two next paragraphs of this section). We also found that the single scratch $A$ and scratch $B$ genes of Lottia are on a same genomic scaffold, but are not adjacent on this scaffold. As such an association is not found in any other species, its meaning remains elusive. Finally, we found that a snail and a scratch gene are adjacent on a same scaffold in the placozoan Trichoplax. A recent study indicated that Trichoplax has a particularly low rate of local rearrangement in its genome, as compared to other animals such as arthropods, and suggested that the Trichoplax genome may thus have retained some ancestral features in its organization [42]. The linkage of snail and scratch in Trichoplax may therefore correspond to the ancestral situation and point out that the snail and scratch genes have been produced by a tandem duplication during the early evolution of animals. A consequence of the low rate of local rearrangement in Trichoplax is that syntenic regions are observed relative to chordates [42]. Interestingly, we found that, while not adjacent, a snail and a scratch gene are found on the same scaffold in the cephalochordate Branchiostoma. Furthermore, in both mouse and human, one of the snail and one of the scratch genes are located on 

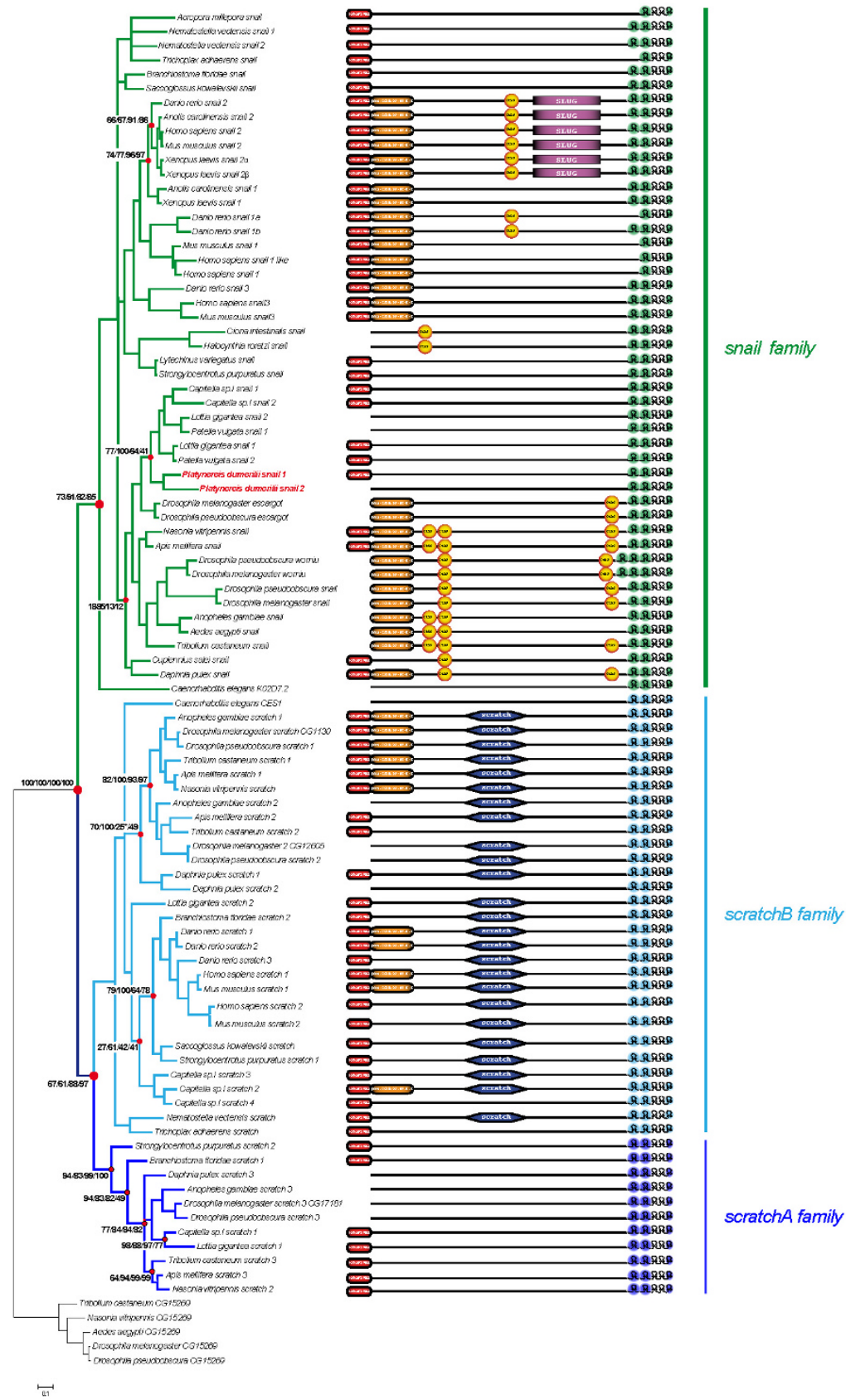

Figure I

Phylogenetic analysis and domain organization of Snail related proteins. The represented tree was constructed by Bayesian inference (BI) and was rooted using the insect CGI5269 proteins as outgroup. This tree is based on a multiple alignment that includes the sequence of all zinc fingers, as well as of SNAG, SCRATCH and SLUG domains when present. Red dots highlight important nodes and their associated numbers represent their statistical support values obtained with different methods of phylogenetic reconstruction: first number = bootstrap support in maximum-likelihood (ML) analysis (I50 bootstrap replicates); second number = posterior probabilities in $\mathrm{BI}$ analysis; third number = bootstrap support in neighbour-joining (NJ) analysis ( 1000 bootstrap replicates); fourth number = bootstrap support in maximum-parsimony (MP) analysis (200 bootstrap replicates). The asterisk associated with the support in the $\mathrm{NJ}$ analysis indicates that in the $\mathrm{NJ}$ tree, this node includes the scratch sequence Caenorhabditis CES-I. The three monophyletic groups, snail, scratchA and scratchB are highlighted using a color code also used in Figures 2B and 3: green, snail genes family; dark blue: scratchA genes family; and light blue, scratchB genes family. Domains of the different proteins are schematically represented on the right of their respective names. 
the same chromosome (but on different arms, in human, 20q13.1 and 20p12.3-13, respectively). We tried to define whether snail and scratch may be included in syntenic regions in Trichoplax, Nematostella, and Branchiostoma, but we failed to detect conserved genes close to snail and scratch in these species (Additional file 4).

We then analyzed in more detail the evolution of the snail and scratch families. For this purpose, we constructed separate phylogenetic trees for these two families (Figure 2). In the case of the snail family, the phylogenetic tree is not well resolved as we found only a few statistically well supported monophyletic groups (Figure 2A). The tree topology was similar to that obtained using the whole dataset of Snail related proteins (Figure 1). Resolution was not increased by analyzing whole sequences or just the $\mathrm{Zn}$-fingers (not shown). Strikingly, almost all statistically supported groups in Figure 2A include sequences only from closely-related species (such as mouse and human or the two gastropods Patella and Lottia) or sequences from the same species (for example in the case of Platynereis and Capitella). Three groups reflecting deep kinships were nevertheless observed and comprise all vertebrates (pink branches in Figure 2A), all non-bilaterians (green branches), or all protostomes (blue branches) sequences, respectively. The existence of these separated groups, while barely statistically supported, suggest that the last common ancestors of eumetazoans and bilaterians possessed a single snail gene and that increased complexity in the family occurred by independent duplication events in the different eumetazoan lineages. From our phylogenetic analyses and applying the parsimony principle, we deduced that at least 10 independent duplications occurred in the snail family. Some of these duplications much probably correspond to whole genome duplications (WGD), two rounds of WGD during early vertebrate evolution explain the origin of the three paralogs found in the different vertebrate groups, one additional round of WGD in teleost fishes produced the snail1a/snail1 $b$ pair in Danio rerio, and still one more WGD in Xenopus laevis led to the presence of the snail $2 \alpha$ and snail $2 \beta$ paralogs in this species $[43,44]$. Other duplications, in Nematostella, Drosophilids, Platynereis, Capitella, and Gastropods, likely correspond to single-gene (small-scale) duplications. Finally, Homo sapiens SNAIL1-like is an intron-less copy of SNAIL1 and therefore probably derives from a retrotransposition event.

The two scratch families show contrasting evolutions (Figure $2 \mathrm{~B}$ ). In the scratch A family, no further duplication event was detected as there is at most one such gene in the different studied species (Figure 2B; Table 1). Strikingly, while a scratchA gene is found in both protostomes (ecdysozoans and lophotrochozoans) and deuterostomes (in an echinoderm and a cephalochordate) and therefore is ancestral to bilaterians, this gene is absent in vertebrates and urochordates, indicating its loss after the divergence between the urochordate/vertebrate and cephalochordate lineages. As discussed previously, the absence of scratch A sequences in the non bilaterians Nematostella and Trichoplax could be due to the loss of this gene in these species or indicate that the duplication that gave rise to the two scratch families occurred only in bilaterians after their divergence with cnidarians and placozoans. The scratch $\mathrm{B}$ family is more complex: genes of this family are found in all bilaterian lineages and paralogs are observed in most species (Figure 2B; Table 1). As in the case of the snail family, our phylogenetic trees suggest occurrence of several (at least 7 ) independent duplications in the scratch B family: in insects (two genes were already present in the last common ancestor of dipterans, coleopterans and hymenopterans), Daphnia, Capitella (2 duplications), Danio rerio (2 duplications, one of which probably corresponding to the teleost-specific WGD), and Mammals.

We conclude that the snail superfamily is composed of three families which are ancestral at least to bilaterians and maybe to eumetazoans. Two of these families (snail and scratch $B$ ) have been broadly conserved in bilaterians and expanded through multiple independent gene duplications in the different bilaterian lineages. The third family (scratch $A)$, in contrast, did not undergo gene duplication events and has been lost in the urochordate/ vertebrate lineage. We next studied the evolution of the domain organization of the Snail and Scratch proteins.

\section{Evolution of domain organization of Snail related proteins} Snail related proteins bear, in addition to $\mathrm{C} 2 \mathrm{H} 2 \mathrm{Zn}$ fingers, more or less conserved domains found in similar positions inside the protein $[1,2,13,37]$. From amino to carboxyl extremity, one can find (i) a Snail/Gfi1 repressor domain (SNAG domain) supposedly represented in all Snail related proteins (Figure 3A); (ii) binding domains for the Carboxy-terminal Binding Protein (CtBP) corepressor (CtBP domain, present only in some Snail sequences; Figure 3B); (iii) two highly conserved aminoacid stretches considered specific to Scratch and to vertebrate Snail3 (formerly known as Slug) proteins which are the so-called SCRATCH (Figure 3C) and SLUG (Figure 3D) domains, respectively; and (iv) $\mathrm{C} 2 \mathrm{H} 2 \mathrm{Zn}$ fingers (Figure $3 \mathrm{E}-\mathrm{G})$. We used our extensive dataset of Snail related proteins to further study the organization and presence/ absence of these domains in the different Snail related proteins. We then examined the evolution of the different domains by representing their presence/absence on the phylogenetic tree of the snail superfamily (Figure 1).

The SNAG domain, though initially described as the 20 first amino acids at the N-terminal end of the Snail protein [45], were often restricted in subsequent studies to 

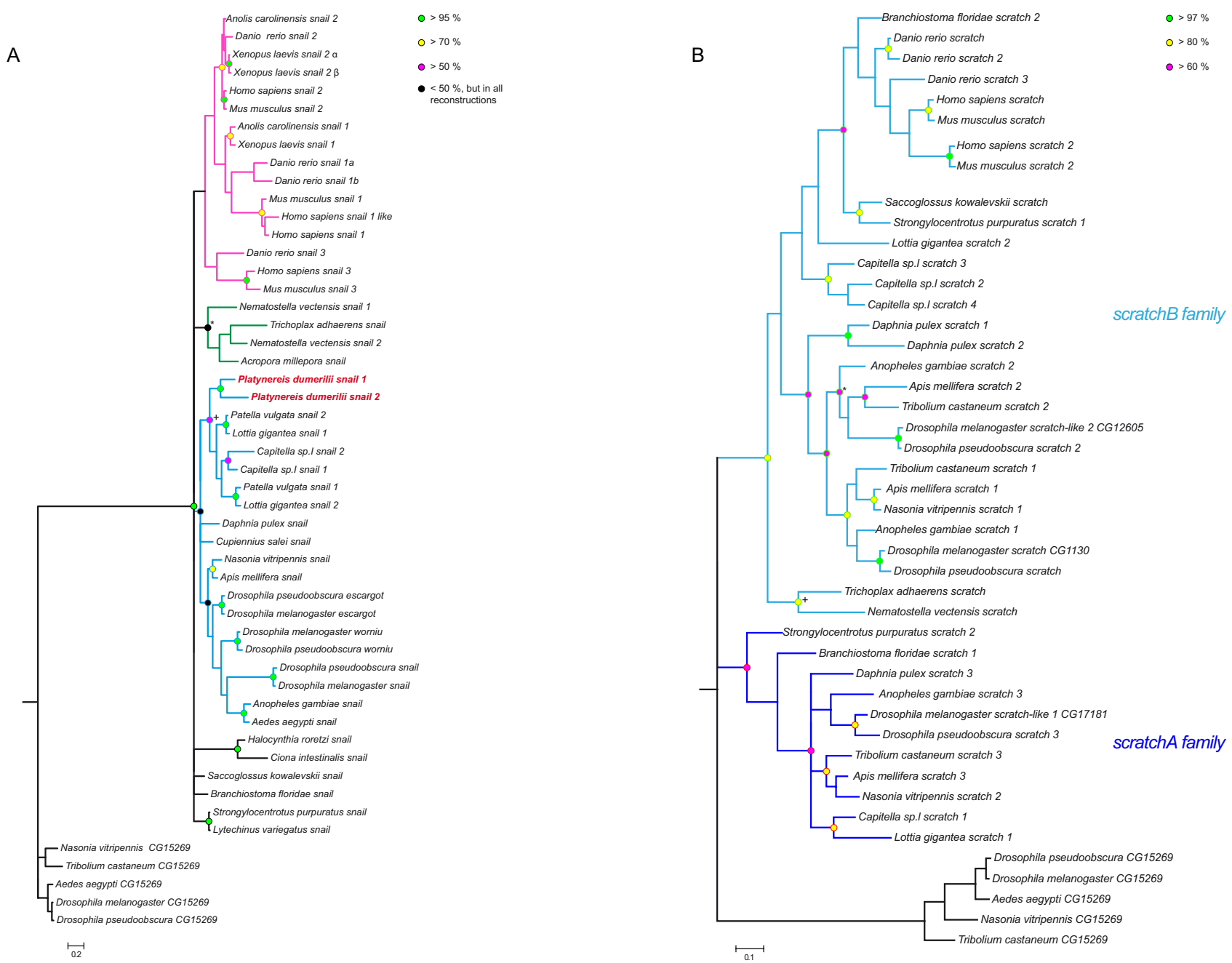

Figure 2

Phylogenetic analysis of snail and scratch families. Trees were taken from BI analyses and rooted using CGI5269 proteins as outgroup. (A) Green dots are placed on nodes supported by more than $95 \%$ in all different methods of phylogenetic reconstruction, yellow dots highlight support over $70 \%$, purple dots over $50 \%$ and black dots below $50 \%$ but found in all reconstructions. $(+)$ indicates that this group is not supported in the MP tree. $\left(^{*}\right)$ indicates that Trichoplax adhaerens Snail was not associated to the cnidarians Snail proteins in the NJ tree. Three poorly supported groups were colored: in purple a group that includes all the vertebrate sequences, in blue all the protostome proteins, and in green the non-bilaterian sequences. (B) Green dots highlight nodes with over $97 \%$ statistical support, yellow over $80 \%$, and purple over $60 \%$. (+) indicates a node where the NJ support value was $54 \%,(*)$ points to a node where the MP statistical support was $45 \%$.

only the first 8 or 9 residues due to poor conservation of the other residues. Thanks to our large dataset covering many species, we found that the SNAG domain is in fact subdivided into two domains (referred to here as SNAG-1 and SNAG-2; Figure 3A). These two domains are rarely simultaneously present in Snail and Scratch proteins (such occurrence can be observed with Daphnia pulex Snail), and more often, only one of the domains is present (for instance SNAG-1 in Homo sapiens SCRATCH2 or SNAG-2 in Drosophila melanogaster Snail), or the two domains are absent (for example in Platynereis dumerilii
Snail2 and Drosophila melanogaster Scratch3). As the SNAG domain is found in proteins belonging to the snail, scratch $A$ and scratch $B$ families (Figure 1 ), this amino-acid stretch is most likely to have been present in the protein encoded by the unique ancestor gene that gave rise to the whole superfamily. This suggests that many convergent secondary losses occurred, either of the entire SNAG domain or of the SNAG-1 or SNAG-2 domains. In our most parsimonious scenario, SNAG-1 loss occurred 11 times to explain its actual repartition in our dataset (this domain is absent in 24 sequences). SNAG-2 seems to be 


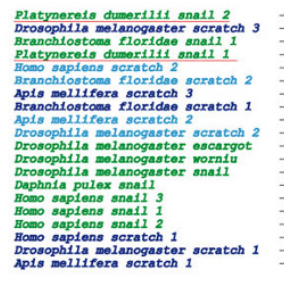

A
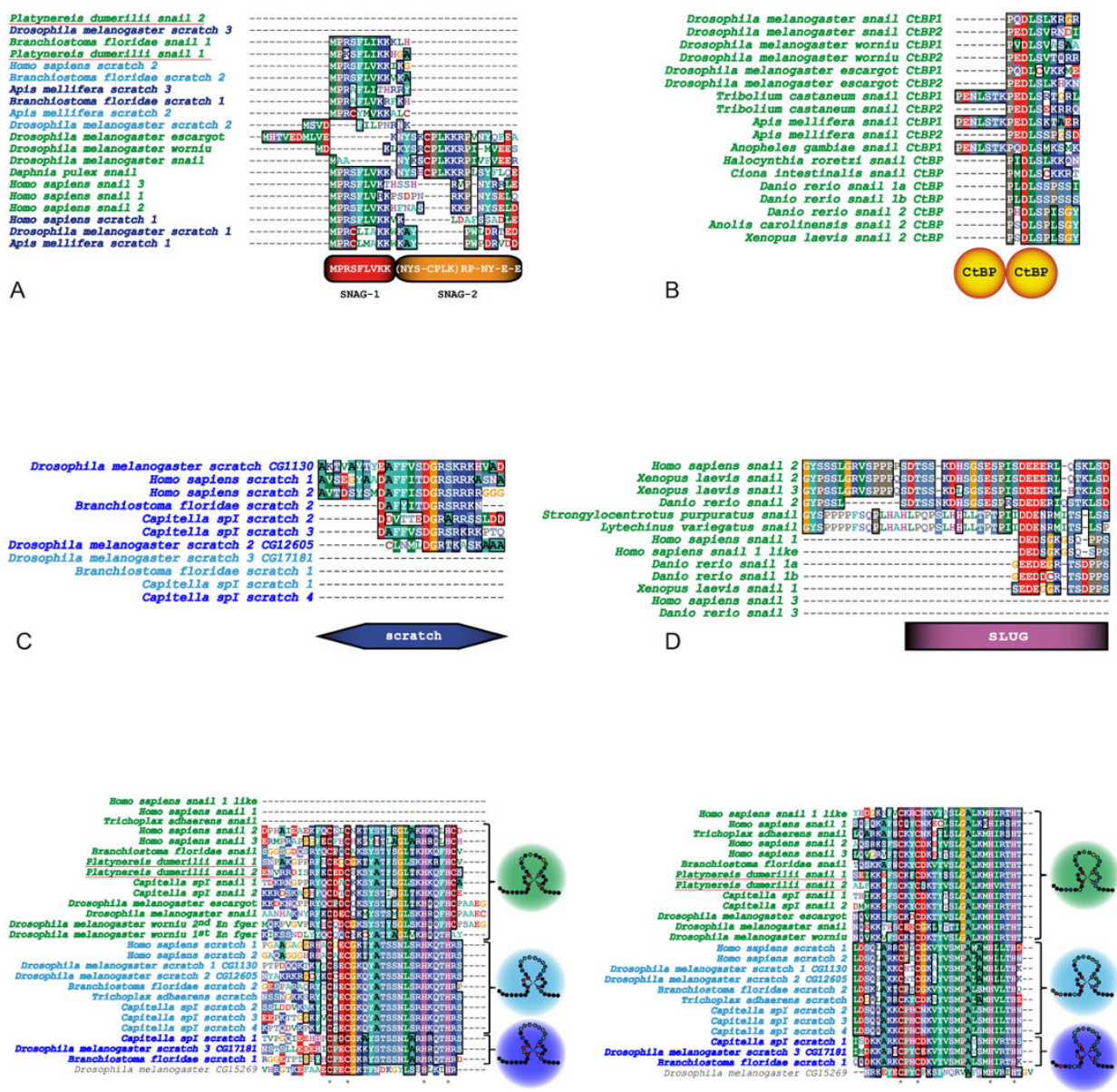

E

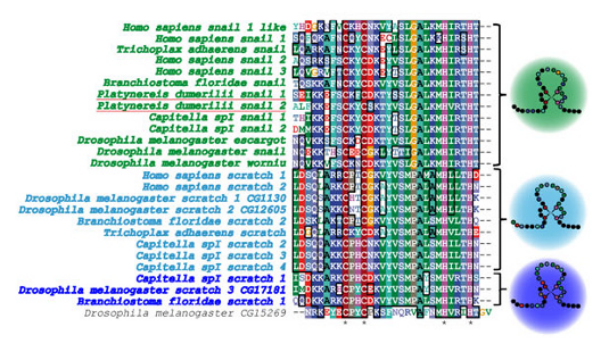

F

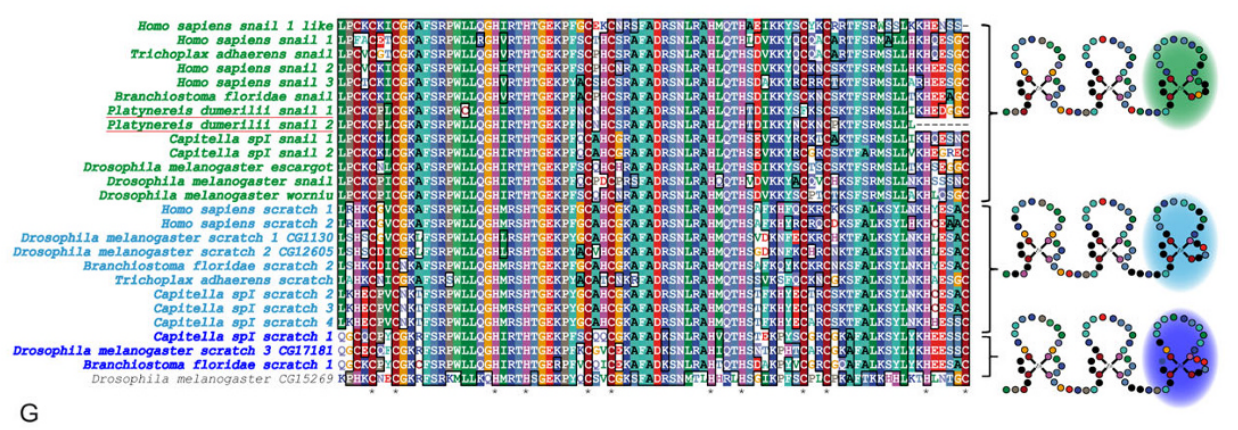

\section{Figure 3}

Conserved domains of Snail and Scratch proteins. Alignment of relevant sequences illustrating all conserved domains found in snail superfamily proteins. Species and gene names are colored using the color code used in Figure I. (A): Alignment of $\mathrm{N}$-terminal SNAG domains. This $2 \mathrm{I}$-amino acids-long domain can be separated in 2 sub-domains (SNAG-I and SNAG-2) that are rarely simultaneously present in snail proteins. (B): Alignment of CtBP domains. These domains are only present in Snail proteins and can be found in tandem or in singleton. (C): Alignment of SCRATCH domains only found in ScratchB proteins.

(D): Alignment of SLUG and similar domains found in some deuterostome Snail proteins. (E, F, G): Alignments of the 5 zinc fingers DNA binding domains characteristic of the snail superfamily. The first, second and last zinc fingers are specific of each subgroup whereas the third and fourth zinc fingers present an overall conservation throughout snail superfamily. Number of zinc fingers can vary by gain (Worniu protein) or loss (Homo sapiens SNAILI) of the first zinc finger. Below alignments, asterisks indicate localization of Cysteines and Histidines forming characteristic $\mathrm{C} 2-\mathrm{H} 2$ motifs. 
even more labile than SNAG-1 and appears to have been lost 18 times independently. Interestingly, variations in the presence of SNAG-1 or SNAG-2 seem to be linked to duplication events, as in several instances SNAG domains are lost in some but not all of the paralogs (Figure 1; for example, snail paralogs in Gastropods and Platynereis, and scratch paralogs in insects, Danio rerio, Mammals and Capitella). The absence or presence of full or partial SNAG domains is likely to have consequences on the activity of the proteins. Indeed, the SNAG domains which are not only present in Snail proteins but also in other Zn-finger transcription factors, may be involved in the transcriptional activity of the protein, as this domain has been shown, in some conditions, to interact with Ajuba LIM Domain Protein to elicit transcriptional repression $[46,47]$.

CtBP domains contain the PXD/LSX motif required for the recruitment of the co-repressor CtBP by Snail proteins, an important event for the function of these proteins as transcriptional repressors (Figure 3B) $[48,49]$. We found this domain to be present only in Snail proteins, but neither in ScratchA nor ScratchB proteins (Figure 1). In both vertebrates and arthropods, we often found a CtBP domain in the N-terminal part of the protein close to the SNAG domain and we suggest that this may represent the ancestral situation for bilaterian Snail proteins. In arthropods, duplications of the motif have occurred, as we often observed two or three CtBP domains, one of which can be found in the C-terminal part of the proteins (Figure 1). As this domain is encoded by a single exon and found in many different proteins, exon shuffling may be responsible for these duplications. Finally, the CtBP domain is absent in all Snail proteins from non bilaterians and lophotrochozoans as well as those from some deuterostomes and insects. This suggests that losses of this domain have occurred and that, contrary to what has been proposed [50], the recruitment of CtBP may not be a conserved modality for the function of Snail proteins in animals. However, the CtBP domain is small and may have some plasticity: we found that in two vertebrates Snail proteins (Anolis and Xenopus Snail1) that lack bona fide CtBP domains, a partially similar motif (PXDLTX) can be found in a similar context (same part of the proteins and conserved amino-acid stretches surrounding the motif) than the CtBP domain in other proteins. It is therefore conceivable that these (and maybe other) Snail proteins lacking bona fide CtBP domains may nevertheless interact with CtBP through altered motifs - functional characterizations of some of these proteins will be required to explore this possibility.

The SCRATCH domain has been described as a conserved amino-acid stretch (of unknown function) found in Scratch but not Snail proteins and therefore as being of diagnostic relevance for the Scratch proteins (Figure 3C) [1]. Despite extensive efforts, we did not find this SCRATCH domain in all Scratch sequences. Strikingly, while this domain is found in most (but not all) ScratchB proteins, we never found it in ScratchA sequences (Figure 1). The SCRATCH domain should thus be considered as a diagnostic domain of scratch B family members (though absent from Daphnia scratch 2, Tribolium scratch 2, Capitella scratch 4 and Trichoplax scratch sequences - Figure 2), but not of the entire scratch family.

A diagnostic stretch of 29 amino-acids was characterized in proteins formerly known as Slug (Snail 2) and was therefore named SLUG domain (Figure 3D) [13]. While the full domain is only found in vertebrate Snail 2 proteins (Figure 1), amino acid stretches similar to part of this domain are found in the single echinoderm Snail protein, as well as in some vertebrate Snail1 and Snail3 proteins (Figure 3D). This suggests that the SLUG domain may have been present in the ancestral deuterostome Snail protein and only well conserved in Snail2 paralogs in vertebrates, as well as to a lesser extent in the echinoderm Snail protein.

Finally, we analyzed the $\mathrm{C} 2 \mathrm{H} 2 \mathrm{Zn}$ fingers sequences (Figure $3 \mathrm{E}-\mathrm{G})$. C2H2 Zn fingers bear a conserved \#-X-C-X(15)-C-X3-\#-X5-\#-X2-H-X(3-6)-[H/C] residues pattern where $\mathrm{X}$ represent any amino acid, and numbers in brackets indicate the number of residues. Positions marked \# are those that are important for stable folding of the zinc finger [51]. Alignment of the Zn-fingers allowed efficient sorting of snail, scratchA, and scratchB family members, with the first and last two Zn-fingers being the most informative (Figure 3E-G). All Scratch and most Snail proteins contain $5 \mathrm{Zn}$-fingers (Figure 1), suggesting that this organization represents the ancestral situation for the snail superfamily. In the snail family, the first Zn-finger has been lost in a few cases (in vertebrates and non bilaterians) and duplicated in Drosophila worniu genes (Figure 1 and Figure 3E), suggesting some plasticity for the presence of this first $\mathrm{Zn}$-finger.

Our careful analysis of the organization of the Snail related proteins allows the identification of diagnostic amino acid stretches, such as the sequence of the first and fifth $\mathrm{Zn}$-fingers and the presence/absence of some domains (for example the SCRATCH domain), specific of either of the three families and which suggest that Snail, ScratchA and ScratchB proteins have different functional specificities. Our analysis also points to potential functional diversifications of the Snail related proteins following gene duplications, as in several instances, paralogs in a given species show different domain organizations (Figure 1). 


\section{Expression patterns of Pdu-snal \& Pdu-sna2 during Platynereis development}

It is widely believed that paralogs may avoid non-functionalization (and therefore be maintained as active genes) over long evolutionary times only if they evolve at least partially different functions (e.g. [52-54]). This could be achieved for example by evolving different or complementary expression patterns. Our phylogenetic analysis of the snail family indicates the occurrence of two independent gene duplications in two polychaete annelids, Platynereis dumerilii and Capitella spI (Figure 1 and Figure 2). We thought that this may represent a good model to study how genes may evolve, at the expression level, following gene duplication. As the expression during development of the two Capitella snail genes have been thoroughly described [23], we studied the developmental expression of the two Platynereis genes (that we named Pdu-sna1 and Pdu-sna2) using whole-mount in situ hybridization (WMISH) with RNA antisense probes. Platynereis displays an indirect development life cycle with a short embryonic development which gives rise to a ciliated trochophore larva that subsequently metamorphoses into a juvenile worm [55]. Throughout the rest of its life, the worm adds segments sequentially from a sub-terminal posterior growth zone. Due to technical difficulty of assessing gene expression in early developmental stages, we focused our studies on Pdu-sna1 and Pdu-sna2 expression from trochophore (24 hours post fertilization, hpf) to adult stage.

In 24 hpf larvae, Pdu-sna1 is expressed in several bilaterally-organized ectodermal cells (Figure 4A, B; blue arrows) whose distribution is similar to that of the cells expressing neural markers, such as Pdu-elav and Pdu-neurogenin [56,57], suggesting that $P d u$-sna1 is expressed in cells of the larval nervous system. In addition, the gene is expressed in internal cells (Figure 4A, B; red arrows) whose organization and position suggest that they belong to the so-called mesodermal bands that will form all the trunk somatic mesoderm derivatives. In 34 hpf larvae, the expression of $P d u$-sna1 in the ectoderm is similar to the previous stage (not shown), but its mesodermal expression has dramatically expanded, as the gene is now expressed in a large number of trunk mesodermal cells (Figure 4D; red arrows). This mesodermal expression is still found in $48 \mathrm{hpf}$ larvae (not shown) in which three additional expression sites can be observed: Pdu-sna1 is expressed in cells that belong to the developing ventral nerve cord (VNC; Figure 4E; filled blue arrows), i.e. the CNS of the worm, in lateral ectodermal cells that probably belong to the developing PNS (Figure 4E; open blue arrows), and in a sheath of cells surrounding the invaginating foregut, i.e. most likely visceral mesodermal cells (Figure 4F; red arrows). All these expression patterns are maintained in subsequent stages, as shown in $72 \mathrm{hpf}$ juvenile worm (Figure 4I, J). At this stage, it is clear that Pdu- sna1 is expressed in the differentiating lateral striated muscles (Figure 4J; red arrows). During adult posterior growth, Pdu-sna1 displays a salt and pepper expression pattern in the growing VNC, as well as in putative PNS cells in more lateral positions (Figure 4M; blue arrows), patterns that are reminiscent to those observed during larval stages. As in $72 \mathrm{hpf}$ larvae, strong expression is also detected in the differentiated lateral striated muscles (Figure $4 \mathrm{~N}$; red arrows).

In 24 hpf larvae, $P d u$-sna2 is expressed in a pattern very similar to that of $P d u$-sna1, suggesting co-expression of the two paralogs in putative larval neural cells (Figure 4C; blue arrows). Pdu-sna2 expression is also found in some ectodermal cells in the episphere of the larva, the future head region (not shown) - no such expression was found for Pdu-sna1. No mesodermal expression is observed for Pdu-sna2 in 24 hpf larvae or subsequent developmental stages. In 48 hpf larvae, Pdu-sna2 is expressed in numerous cells belonging to the prospective $\mathrm{VNC}$, as well as in lateral putative PNS cells (Figure 4G; filled and open blue arrows, respectively). While these expression patterns are reminiscent to those of $P d u$-snal at the same stage, $P d u$ sna2 is clearly expressed in many more cells, in particular in the VNC. In addition, while Pdu-sna1 is mainly expressed in the ventralmost cells of the VNC, Pdu-sna2 is mainly expressed in more lateral VNC cells (compare Figure $4 \mathrm{E}$ and $4 \mathrm{G}$ ), indicating that the two genes have distinct expression patterns in the VNC with little or no overlap. The 48 hpf larval developing VNC region is complex and composed of at least three layers of cells formed by the superficial proliferating neuroectodermal cells, the slightly more internal undifferentiated neural precursors, and the internal differentiated neural cells [56,57]. Using confocal scanning laser microscopy, we determined that $P d u$-sna2 is mainly expressed in the intermediate layer and in a few superficial cells (Figure 5A, C), indicating an expression in undifferentiated neural precursors. At 48 hpf, an expression of Pdu-sna2 is also observed in cells of the invaginating foregut (Figure $4 \mathrm{H}$ and $5 \mathrm{~B}$; white arrows) - once more this expression is clearly distinct from the expression of Pdu-sna1 in the mesodermal sheath of the foregut (compare Figure $4 \mathrm{~F}$ and $4 \mathrm{H}$ ). Pdu-sna2 is also expressed in many cells in the head region, probably corresponding to brain and sense organ cells (not shown). Expressions of $P d u$-sna2, similar to those of the previous stages, are observed in $72 \mathrm{hpf}$ juvenile worms (Figure $4 \mathrm{~K}$, L) and during adult posterior growth (Figure 4O). In a 72 hpf, a very large expression is found in the foregut, suggesting that most of its cells express Pdu-sna2 (Figure $4 \mathrm{~K}$, L; white arrows).

In summary, we have found that both Pdu-sna1 and Pdusna2 are expressed in the developing nervous system, but in at least partially distinct patterns. In addition, Pdu-sna1 

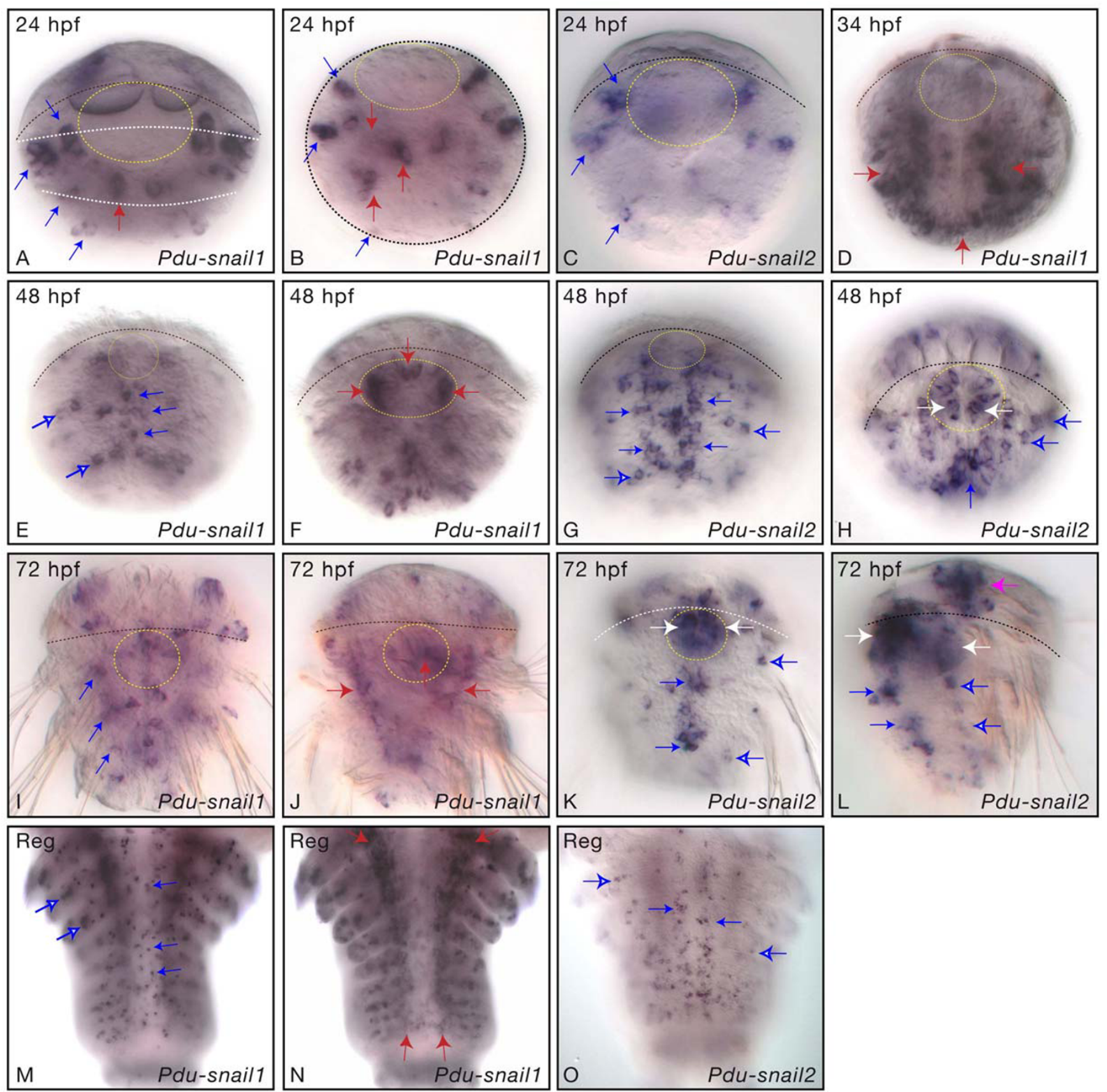

\section{Figure 4}

Developmental expression of Pdu-snal and Pdu-sna2. All pictures are ImageJ projections from WMISH for Pdu-snal or Pdu-sna2 on a selection of larval stages (A-L) and posterior growth (M-O). Posterior growth has been investigated in regenerating posterior part of adult worms (indicated as 'reg'). (A, C-K, M-O) are ventral views with anterior up, (B) is an optical section of the larva (ventral is up) shown in (A) at the level of the trunk (position is indicated by the white dashed lines on picture $A)$, and (L) is a lateral view with ventral side on the left. Black dashed lines delimit the prototroch and the yellow dashed circles surround the stomodeum (closing blastopore in $24 \mathrm{hpf}$ larvae and developing foregut in the next stages). Blue arrows point to neural cells expressing Pdu-snal or Pdu-sna2, filled blue arrows point to cells belonging to the ventral nerve cord and open blue arrows to cells of the peripheral nervous system. Red arrows point to Pdu-snal-expressing mesodermal cells. White arrows point to Pdu-sna2-expressing cells belonging to the foregut and the pink arrow to an expression in the developing brain and/or head sense organs. 
(but not Pdu-sna2) is expressed in parts of the somatic and visceral mesoderm, and Pdu-sna2 (but not Pdu-sna1) in the developing foregut. The expression patterns can be interpreted along two lines. First, if we compare these expressions with those of snail genes in distantly-related species, such as arthropods and chordates, we can highlight putative evolutionary conserved expressions of the genes of this family. A prominent expression in the developing nervous system appears to be such a conserved feature, as it is found in ecdysozoans (for example in insects and spiders; see introduction), in lophotrochozoans (at least in annelids), and in deuterostomes. Indeed, while snail neural functions in vertebrates have been mostly described in the neural crest, a tissue considered to be vertebrate-specific, it has been shown that snail genes are also broadly expressed in the developing neural tube, in a cephalochordate, amphioxus [18], and in a sea lamprey [12]. These data are therefore consistent with an ancestral role of snail family in the formation of the nervous system, both in the PNS and CNS, the expression in the latter having been lost for some vertebrates (gnathostomes). Simi- larly, expression of snail genes in developing mesoderm and mesodermal derivatives is a recurrent theme found in many species belonging to both protostomes (insects) and deuterostomes (vertebrates), suggesting that it may represent a conserved ancestral feature of this gene family.

The expression patterns of Platynereis snail genes elicit another interesting line of interpretations when these patterns are compared with those of another annelid, Capitella spI [23]. In both annelid species, the two paralogs (which have been produced by independent duplications, see above) are expressed in largely distinct patterns. Taken together, the combined expressions of the two snail genes for both species are almost identical, as the genes are broadly expressed in the CNS and the PNS, in the differentiating mesoderm as well as in the foregut, indicating well conserved expressions and probably functions in annelids. Interestingly, these expressions are differently shared out between paralogs in Platynereis and Capitella. Indeed, CapI-sna1 is expressed in the trunk mesoderm, in many cells of the foregut, and in the CNS (including a
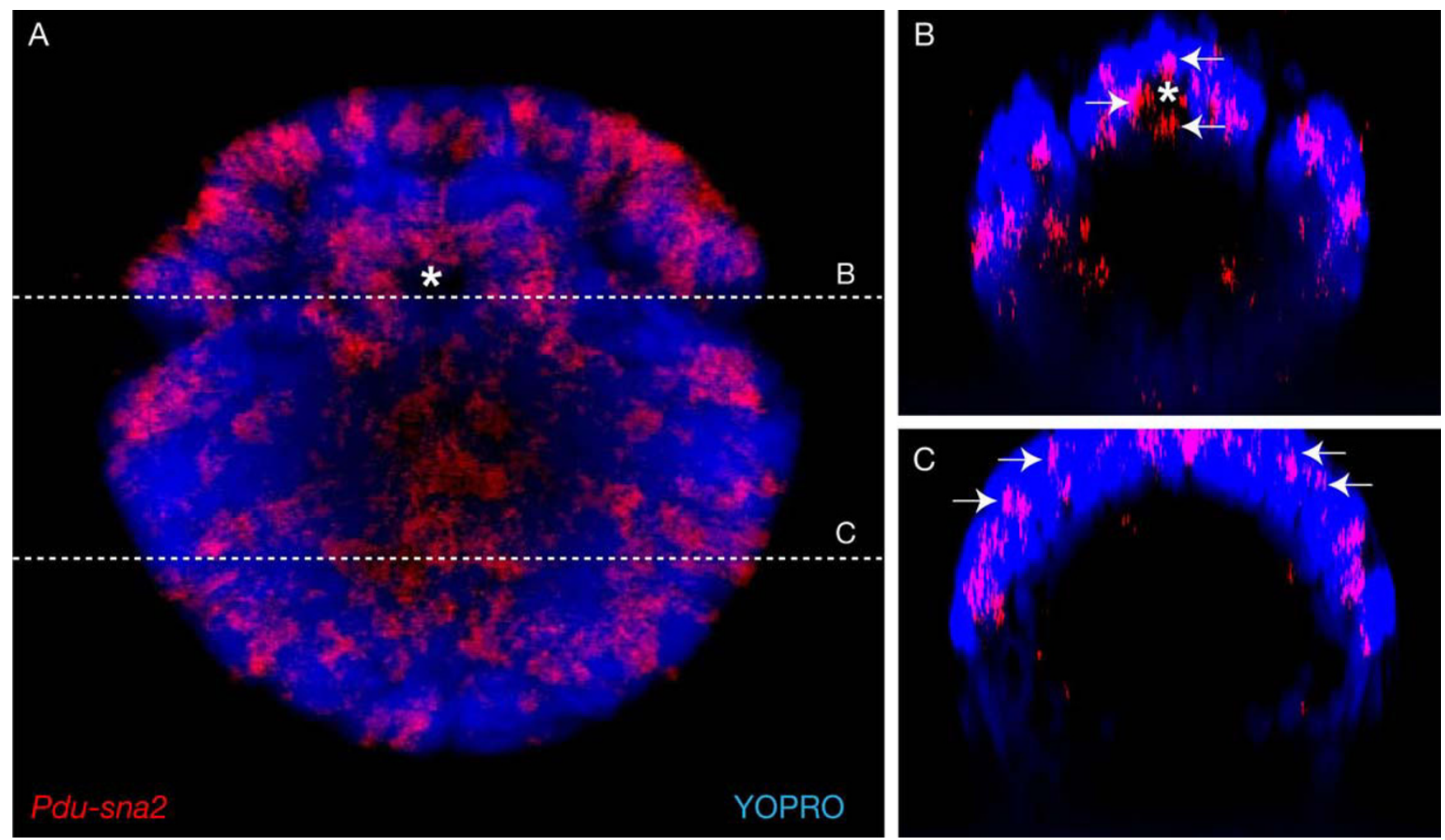

Figure 5

Expression of Pdu-sna2 in neural precursors and foregut cells. $(A)$ is a confocal picture of a WMISH showing expression of Pdu-sna2 in the developing VNC and the foregut. The asterisk indicates the position of the foregut. (B) and (C) are virtual cross-sections which have been made at the levels indicated by the dashed lines in (A). Apical is up, basal is down. (B) Pdusna2 is expressed in cells belonging to the developing foregut (arrows). (C) Layers of the VNC region have been previously defined [54]. Pdu-sna2 is mainly expressed in the intermediate layer (post-mitotic undifferentiated neural precursors; a few of them are indicated by arrows). 
strong expression in the brain and in the ventral part of the VNC) whereas CapI-sna2 is mainly expressed in the CNS (weakly in the brain and in rather lateral cells of the VNC), as well as transiently in a few cells associated with the foregut [23]. In Platynereis, Pdu-sna1 is expressed in the mesoderm, but not in the foregut cells and only in a limited set of cells of the nervous system whereas $P d u$-sna2 is expressed in many neural cells (including in the brain), in many foregut cells, but not in the mesoderm. We suggest that the different expressions of the paralogs in both Platynereis and Capitella are due to subfunctionalization, a process by which ancestral genetic functions (and often expressions) are shared out between paralogs, following gene duplication, and which is believed to be important for the maintenance of paralogs over long evolutionary times (e.g. [52,53]). The subfunctionalization events occurred independently in the two annelid species, as the duplications are themselves independent, leading to different subdivisions of the ancestral expression (nervous system plus mesoderm plus foregut) in Platynereis and Capitella and therefore different combinations of expressions for the two paralogs in these species. Interestingly, evidence for subfunctionalization has also been reported for vertebrate snail genes [12]. We propose that the repeated occurrence of subfunctionalization events may explain why the snail family has undergone so many independent duplications which lead to the maintenance of functional paralogs. More precisely, the snail genes may be especially prone to subfunctionalization, probably because the ancestral snail genes had complex expression patterns and therefore complex regulatory regions, a feature suitable for subfunctionalization [52], and this would increase the retention of paralogs over long evolutionary times.

\section{Conclusion}

In this article, we present a large scale phylogenomic study of the snail superfamily in metazoans. Thanks to the use of an extended and comprehensive sequence dataset and several phylogenetic methods, we show a new topology for the snail superfamily, with three main families, snail, scratch $A$ and scratch $B$. Our phylogenetic analyses indicate that these three families are ancestral at least to bilaterians and maybe to eumetazoans. These families have been well conserved in bilaterians as members of these families are found in the main bilaterian branches. Two of these families (snail and scratch $B$ ) underwent multiple gene duplications while the third one (scratchA) did not and has been lost in the urochordate/vertebrate lineage. A careful analysis of the organization of the Snail and Scratch proteins encoded by the genome of diverse metazoan species indicates that these proteins, while well conserved overall, show specific molecular signatures, such as particular sequence of the $\mathrm{Zn}$-fingers and the presence/absence of some domains, indicative of functional specificities for
Snail, ScratchA and ScratchB proteins. In addition, analysis of the domains of these proteins highlights potential functional diversification of the Snail and Scratch proteins following gene duplications, as in several instances paralogs in a given species show different domain organizations. We also present the expression patterns of two snail genes in the annelid Platynereis dumerilii, which suggest ancestral functions for bilaterian snail genes in nervous system and mesoderm formation. Comparisons of the expression domains of these two Platynereis snail paralogs with the expression domains of the two independently duplicated snail paralogs from another annelid, Capitella $s p I$, provide evidence for independent subfunctionalization events which have occurred in these two species. Subfunctionalization events may have been more generally crucial for the evolution of the snail superfamily and may explain the retention of active paralogs in many instances of independent gene duplications.

\section{Methods \\ Cloning and sequencing of Platynereis dumerilii snail sequences}

A small fragment corresponding to a sequence conserved among protostome and deuterostome snail genes was isolated using degenerate primers on $24 \mathrm{hpf}$ and $48 \mathrm{hpf}$ cDNA libraries and the complete coding sequences of the two Platynereis snail genes were amplified using SMART ${ }^{\mathrm{TM}}$ RACE CDNA amplification procedures with gene-specific primers. PCR products were TA cloned into the PCR2.1 vector (Invitrogen), sequenced on an ABI automated sequencer, and used as template to produce labelled antisense RNA probes for whole mount in situ hybridizations (WMISH). Primer sequences and detailed PCR conditions are available upon request. Accession numbers of $P d u$ snail1 and Pdu-snail2 are EMBL:FN185991 and EMBL:FN185992, respectively.

\section{Retrieval of snail and scratch sequences}

snail and scratch genes were retrieved using TBLASTN and BLASTP algorithms [58] on the current assembly and the predicted proteins (if available) of the genomes of the species indicated in Table 1, using the BLAST servers dedicated to these species (Doe Joint Genome Institute, Baylor College of Medicine, Flybase, Genome Sequencing Center, and Ensembl) or the National Center for Biotechnology Information (NCBI) BLAST server (Genomic BLAST databases) [59-64]. Additional BLAST searches were also performed against the NCBI protein TRACE and EST databases in order to identify snail and scratch genes in additional species whose genome is not completely sequenced. Amino acid sequences were subsequently predicted using Geneid, Genscan, and TBLASTN against the NCBI nr protein database $[58,65,66]$ or by manual alignment. All the sequences we have identified are available upon request. 


\section{Phylogenetic analyses}

Multiple alignments were performed with Muscle 3.6 software [67] and were subsequently manually improved. Handling of the multiple alignments was done using BioEdit sequence alignment editor [68]. Unweighted maximum-parsimony (MP) and neighbour-joining (NJ) reconstructions were performed with the PAUP 4.0 program [69]. NJ analyses were done using the BioNJ algorithm [70] and 1000 bootstrap replicates. MP analyses were performed with the following settings: heuristic search of over 200 bootstrap replicates; MAXTREES set at 3000, and other parameters set at default values. Maximum likelihood (ML) analyses were performed with PHYML [71]. PHYML analyses were performed using the WAG amino-acid substitution model [72], the frequencies of amino acids being estimated from the data set, and rate heterogeneity across sites being modelled by two rate categories (one constant and eight $\gamma$-rates). Statistical support for the different internal branches was assessed by bootstrap resampling (150 bootstrap replicates), as implemented in PHYML [71]. Bayesian inference was performed using the Markov chain Monte Carlo method as implemented in the MRBAYES (version 3) package $[73,74]$. We used the WAG substitution frequency matrix [66] with among-sites rate variation modelled by means of a discrete distribution with four equally probable categories. Two independent Markov chains were run, each containing from $1,500,000$ to $3,000,000$ Monte Carlo steps (depending on the number of steps required to get chain convergence). One out of every 250 trees was saved. The trees obtained in the two runs were meshed and the first $25 \%$ of the trees were discarded as 'burnin'. Marginal probabilities at each internal branch were taken as a measure of statistical support. All the alignments and the trees are available upon request.

Breeding culture, embryo collection, whole mount in situ
hybridization (WMISH), microscopy, and image processing Animals were obtained from a breeding culture established in Gif-sur-Yvette according to the protocol of Fisher and Dorresteijn [55]. Larvae and regenerated posterior parts collection and fixation, as well as WMISH, were done as previously described [75-77]. In some cases, the NBT/BCIP staining was visualized by reflection confocal laser scanning microscopy [75]. Labeled embryos picture Z-stacks were manually taken on a Leica bright-field microscope and Z-projection images were made using ImageJ 1.36b. Confocal pictures were taken on a Leica Sp2 confocal microscope and images were $3 \mathrm{D}$ reconstructed with Metamorph.

\section{Authors' contributions}

$\mathrm{PK}$ and $\mathrm{JH}$ retrieved the sequences, made the sequence alignments, cloned the Platynereis snail genes, and performed most of the in situ hybridizations. PK and MV car- ried out the phylogenetic analyses. JB and MLG performed some of the in situ hybridizations. MV and GB participated in the design and coordination of the study. PK and MV drafted the manuscript and all the authors participated in editing of the manuscript. All the authors read and approved the final manuscript.

\section{Additional material}

\section{Additional file 1}

List of all the sequences used in our study in fasta format. The sequence of the proteins are given. Nucleotide sequences are available on request. Click here for file

[http://www.biomedcentral.com/content/supplementary/14712148-9-94-S1.pdf]

\section{Additional file 2}

Multiple alignment of the conserved domains of the Snail related proteins. This alignments only show the conserved domains of the Snail related proteins and has been used to construct the phylogenetic tree shown in Figure 1.

Click here for file

[http://www.biomedcentral.com/content/supplementary/14712148-9-94-S2.pdf]

\section{Additional file 3}

Genomic localization of the snail and scratch genes in species whose genome is completely sequenced

Click here for file

[http://www.biomedcentral.com/content/supplementary/14712148-9-94-S3.pdf]

\section{Additional file 4}

Maps of the scaffolds that contain the snail and scratch genes in Trichoplax, Nematostella, and Branchiostoma. The portion of the genome that includes the snail and scratch genes is schematically depicted. The name of the genes that flank the snail and scratch genes are those indicated in the genome browsers of the different species.

Click here for file

[http://www.biomedcentral.com/content/supplementary/14712148-9-94-S4.pdf]

\section{Acknowledgements}

We are extremely grateful to the Department of Energy (DoE) Joint Genome Institute, the Baylor College of Medicine (BCM-HGSC), the J. Craig Venter Institute, the Genome Sequencing Center (Washington University in St Louis, School of Medicine), and the National Human Genome Research Institute for sequencing the genomes of the different species used in this study and for making these sequences publicly available. We are also very grateful to the scientists who set up and led these projects. We are grateful to Prof. Maja Nowakowski (State University of New York) for helpful comments on the manuscript. This work was supported by grants from the Agence National de la Recherche "Programme blanc" (to GB) and the CNRS. P.K. held a "Bourse pour Docteur-Ingénieur" from the CNRS and is supported by the Universite Paris Diderot - Paris 7. We thank the Imaging and Cell Biology facility of the IFR87 (FR-W225I) for expert support with confocal microscopy. 


\section{References}

I. Manzanares M, Locascio A, Nieto MA: The increasing complexity of the Snail gene superfamily in metazoan evolution. Trends Genet 200I, I7(4): I78-I8I.

2. Nieto MA: The snail superfamily of zinc-finger transcription factors. Nat Rev Mol Cell Biol 2002, 3(3): I55-166.

3. Boulay JL, Dennefeld C, Alberga A: The Drosophila developmental gene snail encodes a protein with nucleic acid binding fingers. Nature 1987, 330(6 I 46):395-398.

4. Sommer RJ, Retzlaff M, Goerlich K, Sander K, Tautz D: Evolutionary conservation pattern of zinc-finger domains of Drosophila segmentation genes. Proc Natl Acad Sci USA 1992, 89(22): I0782-10786.

5. Sommer RJ, Tautz D: Expression patterns of twist and snail in Tribolium (Coleoptera) suggest a homologous formation of mesoderm in long and short germ band insects. Dev Genet I994, I 5(I):32-37.

6. Weller M, Tautz D: Prospero and Snail expression during spider neurogenesis. Dev Genes Evol 2003, 2 I 3(I I ):554-566.

7. Yamazaki K, Akiyama-Oda $\mathrm{Y}$, Oda $\mathrm{H}$ : Expression patterns of a twist-related gene in embryos of the spider Achaearanea tepidariorum reveal divergent aspects of mesoderm development in the fly and spider. Zoolog Sci 2005, 22(2): I77-I85.

8. Manzanares M, Blanco MJ, Nieto MA: Snail3 orthologues in vertebrates: divergent members of the Snail zinc-finger gene family. Dev Genes Evol 2004, 2 I 4( I):47-53.

9. Mayor R, Morgan R, Sargent MG: Induction of the prospective neural crest of Xenopus. Development 1995, I 2 I (3):767-777.

10. Nieto MA, Bennett MF, Sargent MG, Wilkinson DG: Cloning and developmental expression of Sna, a murine homologue of the Drosophila snail gene. Development 1992, I I 6(I):227-237.

II. Nieto MA, Sargent MG, Wilkinson DG, Cooke J: Control of cell behavior during vertebrate development by Slug, a zinc finger gene. Science 1994, 264(5 I 60):835-839.

12. Rahimi RA, Allmond J], Wagner H, McCauley DW, Langeland JA: Lamprey snail highlights conserved and novel patterning roles in vertebrate embryos. Dev Genes Evol 2008, 2 I9(I):31-36.

13. Sefton $M$, Sanchez S, Nieto MA: Conserved and divergent roles for members of the Snail family of transcription factors in the chick and mouse embryo. Development 1998, | 25( | 6):3 | | |-3 | 2|

14. Thisse C, Thisse B, Postlethwait JH: Expression of snail2, a second member of the zebrafish snail family, in cephalic mesendoderm and presumptive neural crest of wild-type and spadetail mutant embryos. Dev Biol I995, I 72(I):86-99.

I5. Nakakura EK, Watkins DN, Schuebel KE, Sriuranpong V, Borges MW, Nelkin BD, Ball DW: Mammalian Scratch: a neural-specific Snail family transcriptional repressor. Proc Natl Acad Sci USA 200I, 98(7):4010-40I5.

16. Corbo JC, Erives A, Di Gregorio A, Chang A, Levine M: Dorsoventral patterning of the vertebrate neural tube is conserved in a protochordate. Development 1997, I 24( I 2):2335-2344.

17. Hardin J, Illingworth CA: A homologue of snail is expressed transiently in subsets of mesenchyme cells in the sea urchin embryo and is down-regulated in axis-deficient embryos. Dev Dyn 2006, 235(I I):3I2I-3I3I.

18. Langeland JA, Tomsa JM, Jackman WR Jr, Kimmel CB: An amphioxus snail gene: expression in paraxial mesoderm and neural plate suggests a conserved role in patterning the chordate embryo. Dev Genes Evol 1998, 208(1 0):569-577.

19. Shimeld SM: C2H2 zinc finger genes of the Gli, Zic, KLF, SP, Wilms' tumour, Huckebein, Snail, Ovo, Spalt, Odd, Blimp-I, Fez and related gene families from Branchiostoma floridae. Dev Genes Evol 2008, 2 I 8( I I - I 2):639-49.

20. Fritzenwanker JH, Saina M, Technau U: Analysis of forkhead and snail expression reveals epithelial-mesenchymal transitions during embryonic and larval development of Nematostella vectensis. Dev Biol 2004, 275(2):389-402.

21. Martindale MQ, Pang K, Finnerty JR: Investigating the origins of triploblasty: 'mesodermal' gene expression in a diploblastic animal, the sea anemone Nematostella vectensis (phylum, Cnidaria; class, Anthozoa). Development 2004, I 3 I ( I 0):2463-2474

22. Spring J, Yanze N, Jösch C, Middel AM, Winninger B, Schmid V: Conservation of Brachyury, Mef2, and Snail in the myogenic lin- eage of jellyfish: a connection to the mesoderm of bilateria. Dev Biol 2002, 244(2):372-384.

23. Dill KK, Thamm K, Seaver EC: Characterization of twist and snail gene expression during mesoderm and nervous system development in the polychaete annelid Capitella sp. I. Dev Genes Evol 2007, 2 I 7(6):435-447.

24. Goldstein B, Leviten MW, Weisblat DA: Dorsal and snail homologs in leech development. Dev Genes Evol 2001, 2 I I (7):329-337.

25. Lespinet $O$, Nederbragt $A J$, Cassan $M$, Dictus $W J$, van Loon $A E$, Adoutte A: Characterisation of two snail genes in the gastropod mollusc Patella vulgata. Implications for understanding the ancestral function of the snail-related genes in Bilateria. Dev Genes Evol 2002, 21 2(4): 186-195.

26. Ashraf SI, Hu X, Roote J, Ip YT: The mesoderm determinant snail collaborates with related zinc-finger proteins to control Drosophila neurogenesis. EMBO J 1999, I 8(22):6426-6438.

27. Whiteley M, Noguchi PD, Sensabaugh SM, Odenwald WF, Kassis JA: The Drosophila gene escargot encodes a zinc finger motif found in snail-related genes. Mech Dev 1992, 36(3): I I7-I 27.

28. Roark M, Sturtevant MA, Emery J, Vaessin H, Grell E, Bier E: scratch, a pan-neural gene encoding a zinc finger protein related to snail, promotes neuronal development. Genes Dev 1995, 9(19):2384-2398

29. Alberga A, Boulay JL, Kempe E, Dennefeld C, Haenlin M: The snail gene required for mesoderm formation in Drosophila is expressed dynamically in derivatives of all three germ layers. Development 1991, I I I(4):983-992.

30. Jack J, Myette G: Mutations that alter the morphology of the malpighian tubules in Drosophila. Dev Genes Evol 1999, 209(9):546-554.

31. Fuse N, Hirose S, Hayashi S: Determination of wing cell fate by the escargot and snail genes in Drosophila. Development 1996, I 22(4): 1059-1067.

32. Ashraf SI, IP YT: The Snail protein family regulates neuroblast expression of inscuteable and string, genes involved in asymmetry and cell division in Drosophila. Development 200I, I 28(23):4757-4767.

33. Cai $Y, C$ hia $W$, Yang $X$ : A family of snail-related zinc finger proteins regulates two distinct and parallel mechanisms that mediate Drosophila neuroblast asymmetric divisions. EMBO J 200I, 20(7): I704-17|4.

34. Arora K, Nusslein-Volhard C: Altered mitotic domains reveal fate map changes in Drosophila embryos mutant for zygotic dorsoventral patterning genes. Development 1992 , I | 4(4): 1003-1024.

35. Hemavathy K, Meng X, Ip YT: Differential regulation of gastrulation and neuroectodermal gene expression by Snail in the Drosophila embryo. Development 1997, I24( I9):3683-369I.

36. Parrish JZ, Kim MD, Jan LY, Jan YN: Genome-wide analyses identify transcription factors required for proper morphogenesis of Drosophila sensory neuron dendrites. Genes Dev 2006, 20(7):820-835

37. Barrallo-Gimeno A, Nieto MA: The Snail genes as inducers of cell movement and survival: implications in development and cancer. Development 2005, |32(14):315|-316|.

38. Isaac A, Sargent MG, Cooke J: Control of vertebrate left-right asymmetry by a snail-related zinc finger gene. Science 1997, 275(5304): I 30I-I304.

39. Philippe $H$, Telford MJ: Large-scale sequencing and the new animal phylogeny. Trends Ecol Evol 2006, 2 I:614-620.

40. Dunn CW, Hejnol A, Matus DQ, Pang K, Browne WE, Smith SA, Seaver E, Rouse GW, Obst M, Edgecombe GD, Sørensen MV, Haddock SH, Schmidt-Rhaesa A, Okusu A, Kristensen RM, Wheeler WC, Martindale MQ, Giribet G: Broad phylogenomic sampling improves resolution of the animal tree of life. Nature 2008 , 452:745-749.

41. Schierwater B, Eitel M, Jakob W, Osigus HJ, Hadrys H, Dellaporta SL, Kolokotronis SO, Desalle R: Concatenated analysis sheds light on early metazoan evolution and fuels a modern "urmetazoon" hypothesis. PLoS Biol 2009, 7:e20.

42. Srivastava $M$, Begovic E, Chapman J, Putnam NH, Hellsten U, Kawashima T, Kuo A, Mitros T, Salamov A, Carpenter ML, Signorovitch AY, Moreno MA, Kamm K, Grimwood J, Schmutz J, Shapiro H, Grigoriev IV, Buss LW, Schierwater B, Dellaporta SL, Rokhsar DS: 
The Trichoplax genome and the nature of placozoans. Nature 2008, 454:955-960.

43. Panopoulou G, Poustka AJ: Timing and mechanism of ancient vertebrate genome duplications - the adventure of a hypothesis. Trends Genet 2005, 21:559-567.

44. Evans BJ: Genome evolution and speciation genetics of clawed frogs (Xenopus and Silurana). Front Biosci 2008, 13:4687-4706.

45. Grimes HL, Chan TO, Zweidler-McKay PA, Tong B, Tsichlis PN: The Gfi-I proto-oncoprotein contains a novel transcriptional repressor domain, SNAG, and inhibits GI arrest induced by interleukin-2 withdrawal. Mol Cell Biol 1996, I6(II):6263-6272.

46. Ayyanathan K, Peng H, Hou Z, Fredericks W], Goyal RK, Langer EM, Longmore GD, Rauscher FJ 3rd: The Ajuba LIM domain protein is a corepressor for SNAG domain mediated repression and participates in nucleocytoplasmic Shuttling. Cancer Res 2007, 67(19):9097-9106.

47. Hou Z, Peng H, Ayyanathan K, Yan KP, Langer EM, Longmore GD, Rauscher FJ 3rd: The LIM protein AJUBA recruits protein arginine methyltransferase 5 to mediate SNAIL-dependent transcriptional repression. Mol Cell Biol 2008, 28( I 0):3 I 98-3207.

48. Nibu Y, Zhang H, Bajor E, Barolo S, Small S, Levine M: dCtBP mediates transcriptional repression by Knirps, Kruppel and Snail in the Drosophila embryo. EMBO J 1998, I7(23):7009-7020.

49. Nibu $Y$, Zhang H, Levine M: Interaction of short-range repressors with Drosophila CtBP in the embryo. Science 1998, 280(5360): $101-104$.

50. Chinnadurai G: Transcriptional regulation by $\mathrm{C}$-terminal binding proteins. Int J Biochem Cell Biol 2007, 39(9): 1593-1607.

5I. Finn RD, Tate J, Mistry J, Coggill PC, Sammut S], Hotz HR, Ceric G, Forslund K, Eddy SR, Sonnhammer EL, et al.: The Pfam protein families database. Nucleic Acids Res 2008, 36:D28I-288.

52. Force A, Lynch M, Pickett FB, Amores A, Yan YL, Postlethwait J: Preservation of duplicate genes by complementary, degenerative mutations. Genetics 1999, I5 I(4): I53 |-1545.

53. Li WH, Yang J, Gu X: Expression divergence between duplicate genes. Trends Genet 2005, 2 I (I I ):602-607.

54. Ohno S: Evolution by Gene Duplication Berlin-Heidelberg-New York: Springer-Verlag; 1970.

55. Fischer A, Dorresteijn A: The polychaete Platynereis dumerilii (Annelida): a laboratory animal with spiralian cleavage, lifelong segment proliferation and a mixed benthic/pelagic life cycle. Bioessays 2004, 26(3):3 14-325.

56. Denes AS, Jékely G, Steinmetz PR, Raible F, Snyman H, Prud'homme $B$, Ferrier DE, Balavoine G, Arendt D: Molecular architecture of annelid nerve cord supports common origin of nervous system centralization in bilateria. Cell 2007, I 29(2):277-288.

57. Simionato E, Kerner P, Dray N, Le Gouar M, Ledent V, Arendt D, Vervoort $\mathrm{M}$ : atonal- and achaete-scute-related genes in the annelid Platynereis dumerilii: insights into the evolution of neural basic-Helix-Loop-Helix genes. BMC Evol Biol 2008, 8: 170.

58. Altschul SF, Madden TL, Schaffer AA, Zhang J, Zhang Z, Miller W, Lipman DJ: Gapped BLAST and PSI-BLAST: a new generation of protein database search programs. Nucleic Acids Res 1997, 25(I 7):3389-3402.

59. The DOE Joint genome institute genome portal [http:// genome.jgi-psf.org/]

60. The Human Genome Sequencing Center, Baylor College of Medicine [http://www.hgsc.bcm.tmc.edu/]

61. FlyBase: a database for Drosophila genetics and molecular biology [http://flybase.org/]

62. The Genome Sequencing center - Washington University of Medicine [http://genome.wustl.edu/genome group index.cgi]

63. The Ensembl Genome Browser [http://www.ensembl.org/ index.html]

64. The National Center for Biotechnology Information [http:// www.ncbi.nlm.nih.gov/]

65. Parra G, Blanco E, Guigo R: GenelD in Drosophila. Genome Res 2000, I0(4):5II-5I5.

66. Burge C, Karlin S: Prediction of complete gene structures in human genomic DNA. J Mol Biol I997, 268(I):78-94.

67. Edgar RC: MUSCLE: multiple sequence alignment with high accuracy and high throughput. Nucl Acids Res 2004, 32(5): $1792-1797$.

68. Hall TA: BioEdit: a user-friendly biological sequence alignment editor and analysis program for Windows 95/98/NT. Nucleic Acids Symposium Series 1999, 41:95-98.
69. Swofford DL: PAUP*: Phylogenetic analysis using parsimony (and other methods) Sunderland, Massachusetts: Sinauer Associates; 2002.

70. Gascuel O: BIONJ: an improved version of the NJ algorithm based on a simple model of sequence data. Mol Biol Evol I997, I4(7):685-695

7I. Guindon S, Gascuel O: A simple, fast, and accurate algorithm to estimate large phylogenies by maximum likelihood. Systematic Biology 2003, 52(5):696-704.

72. Whelan S, Goldman N: A general empirical model of protein evolution derived from multiple protein families using a maximum-likelihood approach. Mol Biol Evol 200I, I 8(5):69 I-9.

73. Ronquist F, Huelsenbeck JP: MrBayes 3: Bayesian phylogenetic inference under mixed models. Bioinformatics 2003, 19(12): 1572-1574.

74. Huelsenbeck JP, Ronquist F: MRBAYES: Bayesian inference of phylogenetic trees. Bioinformatics 200I, I 7(8):754-755.

75. Jekely G, Arendt D: Cellular resolution expression profiling using confocal detection of NBT/BCIP precipitate by reflection microscopy. Biotechniques 2007, 42(6):75I-755.

76. Tessmar-Raible K, Steinmetz PR, Snyman H, Hassel M, Arendt D: Fluorescent two-color whole mount in situ hybridization in Platynereis dumerilii (Polychaeta, Annelida), an emerging marine molecular model for evolution and development. Biotechniques 2005, 39(4):460. 462, 464

77. Saudemont A, Dray N, Hudry B, Le Gouar M, Vervoort M, Balavoine G: Complementary striped expression patterns of NK homeobox genes during segment formation in the annelid Platynereis. Dev Biol 2008, 3 I 7(2):430-43.

Publish with Bio Med Central and every scientist can read your work free of charge

"BioMed Central will be the most significant development for disseminating the results of biomedical research in our lifetime. "

Sir Paul Nurse, Cancer Research UK

Your research papers will be:

- available free of charge to the entire biomedical community

- peer reviewed and published immediately upon acceptance

- cited in PubMed and archived on PubMed Central

- yours - you keep the copyright
BioMedcentral 